Article

\title{
Amplified Fluorescence by ZnO Nanoparticles vs. Quantum Dots for Bovine Mastitis Acute Phase Response Evaluation in Milk
}

\author{
Narsingh R. Nirala and Giorgi Shtenberg * (D) \\ Institute of Agricultural Engineering, ARO, the Volcani Center, Bet Dagan 50250, Israel; niralamn07@gmail.com \\ * Correspondence: giorgi@agri.gov.il; Tel.: +972-50-7795925
}

Received: 25 February 2020; Accepted: 15 March 2020; Published: 18 March 2020

check for updates

\begin{abstract}
Bovine mastitis (BM) is a prominent inflammatory disease affecting the dairy industry worldwide, originated by pathogenic agent invasion onto the mammary gland. The early detection of new BM cases is of high importance for infection control within the herd. During inflammation, various biomarkers are released into the blood circulation, which are consequently found in milk. Herein, the lysosomal activity of $N$-acetyl- $\beta$-D-glucosaminidase (NAGase), a predominant BM indicator, was utilized for highly sensitive clinical state differentiation. The latter is achieved by the precise addition of tetraethyl orthosilicate-coated zinc oxide nanostructures (quantum dots or nanoparticles, individually) onto a conventional assay. Enhanced fluorescence due to the nanomaterial accumulative near-field effect is achieved within real milk samples, contaminated with Streptococcus dysgalactiae, favoring quantum dots over nanoparticles (>7-fold and 3-fold, respectively), thus revealing significant differentiation between various somatic cell counts. The main advantage of the presented sensing concept, besides its clinically relevant concentrations, is the early bio-diagnostic detection of mastitis (subclinical BM) by using a simple and cost-effective experimental setup. Moreover, the assay can be adapted for BM recovery prognosis evaluation, and thus impact on udder health status, producing an alternative means for conventional diagnosis practices.
\end{abstract}

Keywords: mastitis biomarker; $N$-acetyl- $\beta$-D-glucosaminidase; nanoparticles; quantum dots; signal enhancement; zinc oxide

\section{Introduction}

Bovine mastitis (BM) is a prominent inflammatory disease affecting the dairy industry worldwide, originated by pathogenic agent invasion onto the mammary gland [1-3]. Decreased milk production yield, unsatisfying product quality and increased treatment costs are all proportionally correlated to the severity of the occurring BM [4,5]. The disease is classified as chronic, clinical and subclinical based on the induced pathogenesis $[2,6,7]$. The latter ( $>90 \%$ of BM cases) is difficult to detect due to the absence of any visible indications, as in the case of clinical BM (visual milk abnormalities, tissue swelling and redness, systemic illness, etc.) [1,2]. Conventional techniques measure somatic cell counts (SCC), identify causative pathogenic bacteria by selective cell culture diagnosis and assess enzymatic activity $[3,5,8,9]$. Lactate dehydrogenase and $N$-acetyl- $\beta$-D-glucosaminidase (NAGase) are predominant indicators of BM, which correlate with the SCC levels found in milk [3]. These enzymes are released upon damage to or lysis of epithelial cells of the mammary gland, therefore representing augmented health status $[1,6]$. NAGase peripheral distribution in plasma increases (up to an order of magnitude) upon inflammation or infection with respect to healthy conditions [1,3,10,11]. NAGase lysosomal activity is used to differentiate healthy quarters from all other inflamed statuses based on a fluorescence (FL) methodology developed by Kitchen et al. [2,6,12]. Briefly, the method includes 
the specific lysosomal breakdown of 4-methylumbelliferyl- $N$-acetyl- $\beta$-D-glucosaminide (4-MUAG) substrate to fluorogenic products of 4-methylumbelliferone (4-MU) in alkaline conditions [6,12]. Despite the known advantages of the procedure, e.g., being simple, rapid and affordable, it suffers from low quantum efficiency and low sensitivity in differentiating subclinical cases [13]. Our previous report has attempted to overcome these limitations by employing silica-coated zinc oxide ( $\mathrm{ZnO}$ ) quantum dots (QDs) for enhanced FL of the obtained 4-MU product by the conventional NAGase assay [13]. Intensified emission values were achieved in correlation to SCC, pathogen type (coagulase-negative staphylococci and Streptococcus dysgalactiae (Strep. dysgalactiae)) and the severity of the occurring BM without hindering the optical performance.

$\mathrm{ZnO}$ nanostructures (QDs, nanoparticles-NPs, thin-films, nanorods, nanoflowers, etc.) are widely used multifunctional semiconducting materials for complex biosensing applications utilizing their unique physical and chemical properties [14-21]. These nanostructures are optically stable at room temperature, presenting a high exciton energy $(60 \mathrm{meV})$ and wide band-gap (3.36 eV) [18]. Moreover, ZnO nanomaterials absorb UV radiation and thus act as potent signal enhancers for FL-based sensors [15]. The mechanisms behind the FL enhancement are due to the evanescent electric field at the surface of the nanomaterial that increases the excitation energy of the fluorescent molecule [19]. $\mathrm{ZnO}$ is a low-cost material synthesized by various techniques that control size, morphology and functionality (capping agents used to modify its surface include: silanes, polyvinylpyrrolidone, aliphatic thiols and amines) $[13,22]$. Several reports depict the practical usage of $\mathrm{ZnO}$ for FL enhancement across the visible-light spectrum. Tereshchenko et al. have shown a highly sensitive optical biosensor based on $\mathrm{ZnO}$ thin-films for monitoring Grapevine virus type-A, which infects healthy plants [23]. The specific immunorecognition of the target antigen presented correlative luminescence intensity changes around the $425 \mathrm{~nm}$ band. The optical response depicted a wide dynamic range of $1 \mathrm{pg}$ to $10 \mathrm{ng} \mathrm{mL}^{-1}$ with high selectivity and applicability for on-site detection. A similar concept using FITC-modified antibodies for cancer biomarkers' detection has shown multiplex bio-detection capabilities [24]. Polyethylenimine-modified $\mathrm{ZnO}$ nanowires impregnated by microfluidics channels enhanced the inherent FL signal for human $\alpha$-fetoprotein and carcinoembryonic antigen detection over 6-7 orders of magnitude, while presenting detection limits of $1 \mathrm{pg} \mathrm{mL}^{-1}$ and $100 \mathrm{fg} \mathrm{mL}^{-1}$, respectively. Akhtar et al. have modified $\mathrm{ZnO}$ nanoflowers grown over silver thin-films with Thioflavin $\mathrm{T}$ for the sensitive targeting of amyloids as an early diagnosis methodology for different neurodegenerative disorders [25]. Enhanced FL, by 9.8-fold, was obtained upon insulin amyloid binding to the nanobiosensor, reinforcing the excitation of fluorophore molecules in close proximity with $\mathrm{ZnO}$.

Herein, a comparative study evaluated the lysosomal activity of NAGase by FL signal amplification in the presence of silica-coated $\mathrm{ZnO}-\mathrm{QDs}$ and $\mathrm{ZnO}-\mathrm{NPs}$. The synthesized nanomaterials were optically and chemically characterized for optimal FL signal amplification. Different milk qualities at three SCC levels, contaminated with Strep. dysgalactiae, influence on the secreted NAGase content, were evaluated with respect to healthy udder (with and without $\mathrm{ZnO}$ nanomaterials). Overall, the optical performances based on intensified FL signals offered the means to deduce the severity of the occurring BM and the overall udder health with respect to a conventional assay protocol with improved sensitivity.

\section{Materials and Methods}

\subsection{Materials}

Methanol, potassium hydroxide, sodium citrate dihydrate, tetraethyl orthosilicate (TEOS, 98\%) and zinc nitrate hexahydrate (98\%) were purchase from Merck. Ammonium hydroxide water $(28 \%)$, ethanol, 4-MUAG, 4-MU, ZnO nanopowder ( $<100 \mathrm{~nm}$ particle size) and analytical grade buffers were supplied by Sigma-Aldrich. Milli-Q water $(18 \mathrm{M} \Omega \mathrm{cm})$ was used for the denoted experiments. 


\subsection{Fabrication of TEOS Modified $\mathrm{ZnO} \mathrm{O} Q \mathrm{QDS}$}

ZnO-QDs were prepared by a modified protocol previously reported by Parta et al. [18]. Briefly, zinc nitrate hexahydrate $(0.1 \mathrm{M})$ and potassium hydroxide $(0.1 \mathrm{M})$, both methanolic solutions, were mixed for $1 \mathrm{~h}$ while maintaining alkaline conditions. The resulting $\mathrm{ZnO}-\mathrm{QD}$ s were modified with $250 \mu \mathrm{L}$ TEOS for optimized molecular coverage, resulting in $\mathrm{ZnO}-\mathrm{QDs}-\mathrm{SiO}_{2}$ [13]. The colloidal solution was centrifuged (10,000 rpm, $10 \mathrm{~min})$ and washed with methanol three times. The final product was aqueously diluted to $6.5 \mathrm{mg} \mathrm{mL}^{-1}$ before prior use.

\subsection{Fabrication of TEOS Modified $\mathrm{ZnO}-\mathrm{NPS}$}

ZnO-NPs were silica-coated according to a previous study by El-Nahhal et al. [16]. Briefly, $25 \mathrm{mg}$ of $\mathrm{ZnO}$ nanopowder was dispersed in a mixture of ammonium hydroxide, ethanol and milli-Q water $(0.15,10,5 \mathrm{~mL}$, respectively), followed by $30 \mathrm{~min}$ sonication. Next, the dispersion was mixed with TEOS (0-100 $\mu \mathrm{L}$ for optimized molecular coverage) for $24 \mathrm{~h}$ at room temperature, resulting in $\mathrm{ZnO}-\mathrm{NPs}^{-\mathrm{SiO}_{2}}$. The resulting product was centrifuged $(4000 \mathrm{rpm}, 5 \mathrm{~min})$ and washed with ethanol three times. The final product was aqueously diluted to $6.5 \mathrm{mg} \mathrm{mL}^{-1}$ before prior use.

\subsection{Milk Sampling}

Milk samples were obtained by authorized personnel from specific quarters of Holstein cows (Volcani Center research herd) and classified as healthy, subclinical and clinical BM, as previously described [10]. The Institutional Animal Care Committee of ARO approved animal experiments (838/119IL)

\subsection{Quantification of NAGase Activity}

The quantification of NAGase activity was as previously described by Nirala et al. [13]. Milk samples $(30 \mu \mathrm{L})$ were mixed with $40 \mu \mathrm{L}$ of substrate $(2.25 \mathrm{mM} 4$-MUAG) or $40 \mu \mathrm{L}$ of the product $(0$ to $100 \mu \mathrm{M}$ of 4-MU) in acidic conditions (citrate buffer, $\mathrm{pH}$ 4.6). The reaction solution was mixed on an automatic shaker for $1 \mathrm{~min}$ with $100 \mu \mathrm{L}$ of optimized $\mathrm{ZnO}$ nanomaterial concentration $(0-6.5 \mathrm{mg}$ $\mathrm{mL}^{-1}$ for $\mathrm{ZnO}-\mathrm{QDs}-\mathrm{SiO}_{2}$ and $\mathrm{ZnO}-\mathrm{NPs} \mathrm{SiO}_{2}$ ). Finally, end-point $\mathrm{FL}$ studies were carried using $365 \mathrm{~nm}$ excitation and measuring the FL after 12 min of reaction.

\subsection{Instrumentation}

UV-VIS absorption spectra and FL studies were analyzed with Varioskan ${ }^{\mathrm{TM}}$ LUX (by Thermo Scientific, Waltham, MA, USA), a multimode microplate reader [11]. The structural morphology and size of the different ZnO NPs and QDs were studied by Tecnai G2, FEI cryo transmission electron microscopy (TEM), operated at $120 \mathrm{kV}$ (Hillsboro, OR, USA) and by dynamic light scattering (DLS) using a Zetasizer Nano ZS (Malvern Instruments Ltd., Malvern, UK). Surface modification was characterized by attenuated total reflectance Fourier transform infrared (ATR-FTIR) spectroscopy using Thermo Scientific Nicolet iS50 (Madison, WI, USA) [26]. Elemental analysis was characterized by energy-dispersive X-ray spectroscopy (EDX) detector using MIRA3 field-emission SEM microscope (TESCAN, Kohoutovice, Czech Republic) operated at acceleration voltage of $10 \mathrm{kV}$.

\section{Results and Discussion}

\subsection{ZnO-Nanomaterials Characterization}

Alkoxyl silanes are widely used for the surface modification of various nanomaterials and films for numerous applications $[14,17,27]$. Herein, TEOS molecules were applied on $\mathrm{ZnO}$ nanomaterials (NPs and QDs) via hydrolysis in aqueous media followed by polycondensation of alkoxyl groups in alkaline conditions, thus resulting in silica-coated $\mathrm{ZnO}$-nanomaterials [18,21]. The addition of silica molecules stabilizes the colloidal aqueous solution and inhibits the time-dependent nucleation and 
precipitation of adjacent nanomaterials $[18,20]$. Surface modifications of both nanomaterials were characterized by UV-VIS spectroscopy. Figure 1a,b show the absorbance spectra of ZnO-QDs and $\mathrm{ZnO}-\mathrm{NPs}$ before and after TEOS coating, respectively. The characteristic absorbance shoulder peak of $\mathrm{ZnO}-\mathrm{QD}$ s blue shifts from 340 to $310 \mathrm{~nm}$ upon silica-coating (Figure 1a). The shift can be ascribed to the decrease in particle diameter due to the quantum confinement effect upon TEOS modification, as previously shown $[16,22,28,29]$. An opposite optical trend is shown for ZnO-NPs upon similar surface modification, where a red shift from 364 to $372 \mathrm{~nm}$ was obtained in the resulting $\mathrm{ZnO}-\mathrm{NPs}-\mathrm{SiO}_{2}$ upon mild augmentations in particle size (Figure 1b). The silica capping was further characterized by ATR-FTIR studies shown in Figure 1c,d for ZnO-QDs and ZnO-NPs, respectively. The characteristic absorption peaks of as-prepared $\mathrm{ZnO}-\mathrm{QDs}$ depict a $\mathrm{Zn}-\mathrm{O}$ stretching vibration at $421 \mathrm{~cm}^{-1}$, hydroxyl groups stretching vibration at 1649 and $3273 \mathrm{~cm}^{-1}$, and nitrate precursor residues peak at $1375 \mathrm{~cm}^{-1}$, accredited to $\mathrm{N}-\mathrm{O}$ vibration (Figure 1c) $[14,30]$. The silica capping by TEOS molecules is shown by the additional peak at $969 \mathrm{~cm}^{-1}$ for the $\mathrm{ZnO}-\mathrm{QDs}-\mathrm{SiO}_{2}$ spectrum, known as an asymmetric vibration of $\mathrm{Si}-\mathrm{O}-\mathrm{Si}[13,16]$. Figure $1 \mathrm{~d}$ depicts similar characteristic peaks of $\mathrm{Zn}-\mathrm{O}$ and $\mathrm{O}-\mathrm{H}$ at 416 and $3282 \mathrm{~cm}^{-1}$, respectively, and the addition of siloxane peak at $1053 \mathrm{~cm}^{-1}$ [18]. Overall, the new characteristic peaks of both $\mathrm{ZnO}$ nanomaterials following TEOS modification suggest a silica shell creation. To further elucidate the latter statement, elemental composition analysis by EDX detector was performed. Figures $\mathrm{S} 1$ and S2 present the elemental composition spectra and the relative atomic percentage of ZnO-QDs and $\mathrm{ZnO}-\mathrm{NPs}$, respectively, before and after TEOS coating. Indeed, both $\mathrm{Si}$ and O elements are increased following silica capping, while the $\mathrm{Zn}$ values are minimized for $\mathrm{ZnO}-\mathrm{QDs}-\mathrm{SiO}_{2}$ and $\mathrm{ZnO}-\mathrm{NPs}-\mathrm{SiO}_{2}$. These results are in agreement with ATR-FTIR and UV-VIS spectral analysis, verifying the silica-coating formation. Finally, the structural dimensions of $\mathrm{ZnO}-\mathrm{QDs}-\mathrm{SiO}_{2}$ and $\mathrm{ZnO}-\mathrm{NPs}-\mathrm{SiO}_{2}$ were characterized by TEM. Figure 1e depicts the spherical shaped particles within the range of $7.3 \pm 0.7 \mathrm{~nm}$ (applicative for the quantum confinement effect range), while the silica-coated ZnO-NPs present a mixture of different sizes and shapes at approximately $84 \pm 37 \mathrm{~nm}$ (Figure 1f). To further strengthen the physical dimensions and size distribution, DLS measurements were performed on TEOS-coated nanomaterials. Indeed, similar features are obtained for $\mathrm{ZnO}-\mathrm{QDs}-\mathrm{SiO}_{2}(5.2 \pm 2.4 \mathrm{~nm}, \mathrm{PDI}$ of 0.121$)$ and $\mathrm{ZnO}-\mathrm{NPs}-\mathrm{SiO}_{2}$ $(109 \pm 33 \mathrm{~nm}$, PDI of 0.405$)$. It should be mentioned that the TEOS coating was not observed in both $\mathrm{ZnO}$ nanomaterials, indicating a thin surface coverage $[13,16]$. 

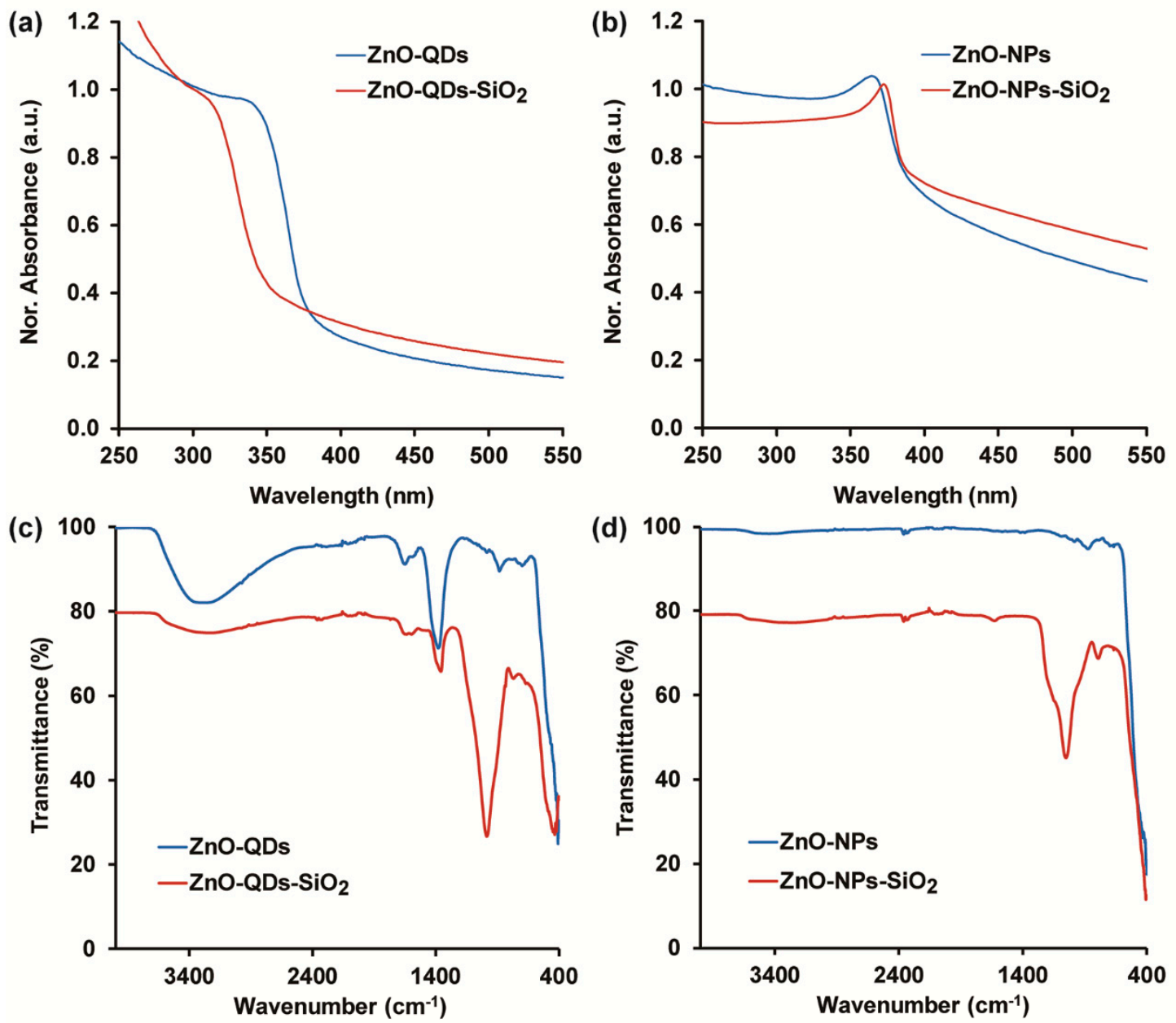

(e)

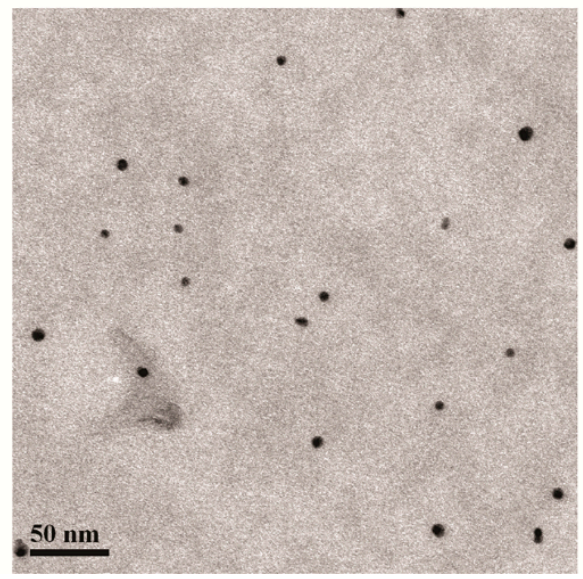

(f)

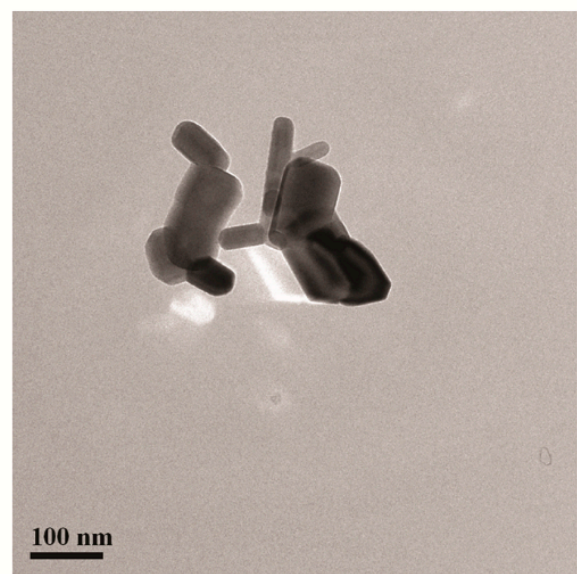

Figure 1. $\mathrm{ZnO}$ nanomaterial characterization before and after tetraethyl orthosilicate (TEOS) modification. UV-VIS spectra of (a) ZnO-QDs and (b) ZnO-NPs; attenuated total reflectance (ATR)-FTIR spectra surface characterization of (c) ZnO-QDs and (d) ZnO-NPs; Representative TEM images of (e) $\mathrm{ZnO}-\mathrm{QDs}-\mathrm{SiO}_{2}$ and (f) $\mathrm{ZnO}-\mathrm{NPs}_{-}-\mathrm{SiO}_{2}$.

\subsection{FL Amplification Characterization}

FL signal enhancement of NAGase biochemical reaction product (4-MU) was characterized in the presence of $\mathrm{ZnO}-\mathrm{QDs}-\mathrm{SiO}_{2}$ and $\mathrm{ZnO}-\mathrm{NPs}-\mathrm{SiO}_{2}$. Previous studies depict significant non-radiative energy transfer between $\mathrm{ZnO}$ nanomaterials to the fluorogenic reaction products $[15,18]$. Herein, optimized silica coverage was utilized for increased electric field modulation, considering excitation 
spectra overlapping and the distance-related proximity of plasmonic nanoparticles with the produced fluorophores $[13,19]$. Figure S3 shows the emission spectra of different TEOS amounts $(0,15,30,45$, 63, 75 and $100 \mu \mathrm{L}$ ) used to coat ZnO-NPs using an excitation wavelength of $365 \mathrm{~nm}$. The maximal FL emission for each condition is obtained at $520 \mathrm{~nm}$, while the FL response is augmented with increasing TEOS coverage up $63 \mu \mathrm{L}$ and decreased thereafter. The maximal signal (63 $\mu \mathrm{L}$ TEOS) was chosen for consecutive studies expecting pronounced FL signal amplification. It should be noted that insignificant FL values ( $<5$ a.u.) are attained for all $\mathrm{ZnO}-\mathrm{NPs}-\mathrm{SiO}_{2}$ conditions at a characteristic $\mathrm{E}_{\mathrm{m}}$ of $450 \mathrm{~nm}$ for the noted biochemical assay. Figure $2 b$ presents the FL emission spectra of NAGase biochemical reaction products (4-MU fixed at $20 \mu \mathrm{M}$ ) with and without $\mathrm{ZnO}-\mathrm{QDs}-\mathrm{SiO}_{2}$ and $\mathrm{ZnO}-\mathrm{NPs}-\mathrm{SiO}_{2}$ in milk and buffer solutions, presenting maximal emission at $450 \mathrm{~nm}$. Silica capping of both $\mathrm{ZnO}$ nanomaterials presents profound signal enhancement in milk media, above 7- and 3-fold for $\mathrm{ZnO}-\mathrm{QDs}_{-} \mathrm{SiO}_{2}$ and $\mathrm{ZnO}-\mathrm{NPs}-\mathrm{SiO}_{2}$, respectively, in comparison to a conventional assay content omitting the addition of these nanomaterials. The insignificant FL intensity values are attained for the milk sample used as a negative control for the assay, while the positive condition (stock 4-MU) showed sufficient indicative fluorescence. The latter values were quenched upon the addition of complex media as milk due to molecular interferences [31]. Subsequently, to further optimize the bioassay efficiency in terms of signal enhancement, both optically active nanomaterials' optimal concentrations within each microplate well assay were evaluated. Each stock $\mathrm{ZnO}$ nanomaterial was serially diluted in aqueous solution and added to the conventional NAGase assay for FL signal assessment [13]. The conventional assay is considered as a standard technique to evaluate NAGase activity within complex samples (i.e., milk, urine) and therefore specifically indicates udder health state [1,6,32]. Briefly, a mixture of $40 \mu \mathrm{L}$ NAGase substrate $(2.25 \mathrm{mM}, 4-\mathrm{MUAG}), 30 \mu \mathrm{L}$ of mastitic milk sample and $100 \mu \mathrm{L}$ of the different TEOS-coated nanomaterials concentrations were allowed to react, while the FL emission of the reaction products was evaluated. It is expected that an increased electric field effect is proportional to surface plasmons' augmentation up to an optimal nanomaterial concentration for sufficient FL signal enhancement, above which the quenching effect is favored (Figure 2a) [15,19]. The latter is ascribed to intrinsic short-range molecular interactions between the produced fluorophore and the $\mathrm{ZnO}$ nanostructures [33,34]. Figure 2c depicts NAGase-specific catalytic reaction output within mastitic milk samples with respect to catalyst content augmentation for $\mathrm{ZnO}-\mathrm{QDs}-\mathrm{SiO}_{2}$ and $\mathrm{ZnO}-\mathrm{NPs}_{\mathrm{S}} \mathrm{SiO}$. Indeed, both nanomaterials' content growth increases the FL intensities up to $2.56 \mathrm{mg} \mathrm{mL}^{-1}$, while further metal increase results in the FL signal's gradual decline up to a maximal ZnO content. Thus, based on the pronounced signal augmentation, the silica-coated $\mathrm{ZnO}$ nanomaterials were set to $2.56 \mathrm{mg}$ $\mathrm{mL}^{-1}$ and were adopted for acute phase response evaluation within different milk samples. 
(a)

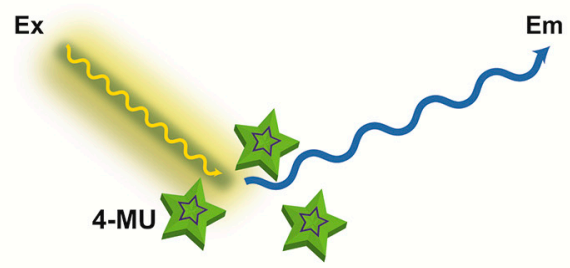

Conventional assay
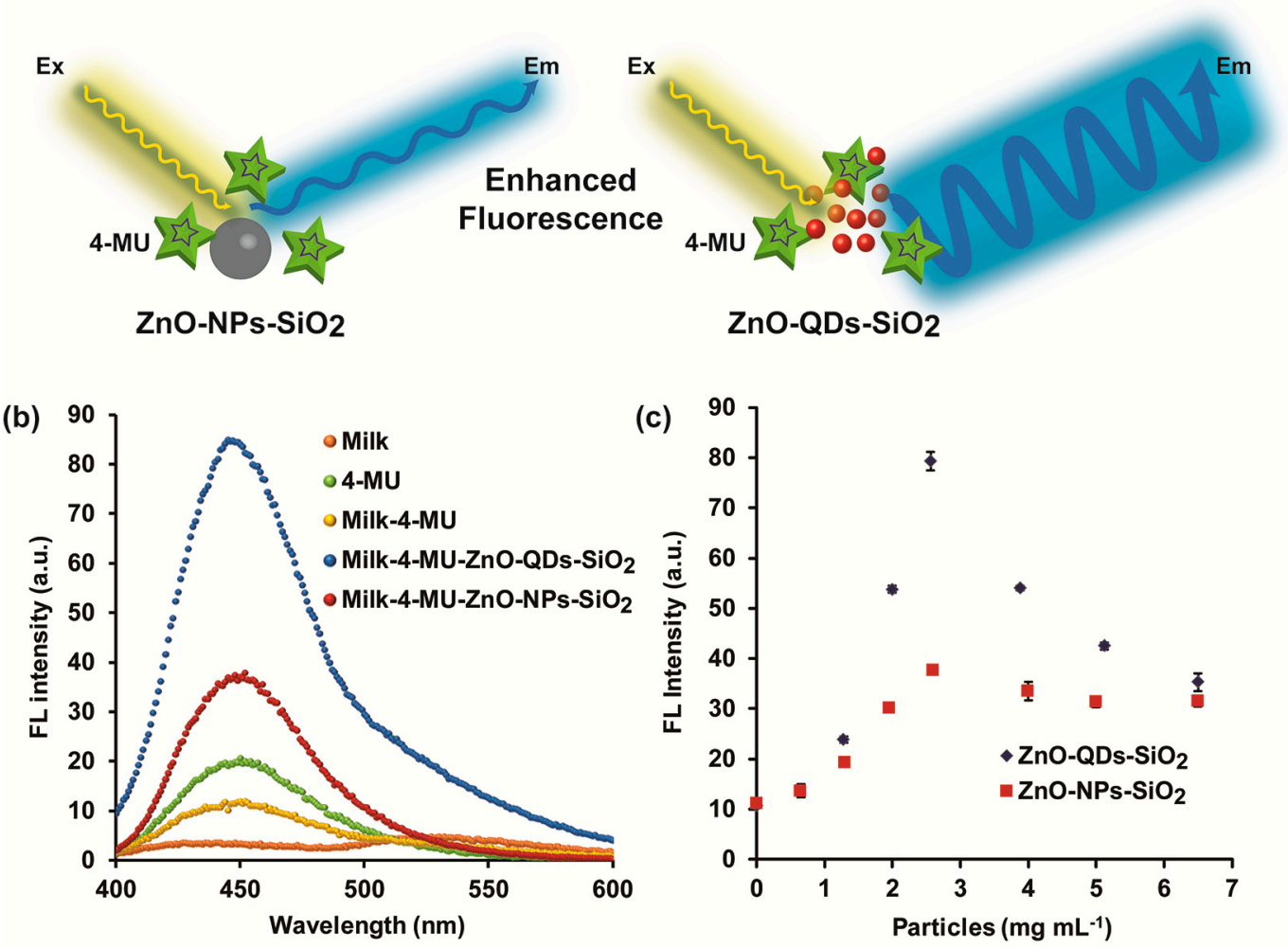

Figure 2. (a) Schematic illustration of FL signal amplification by $\mathrm{ZnO}$ nanomaterials; (b) FL emission spectra of NAGase biochemical reaction products (4-MU fixed at $20 \mu \mathrm{M}$ ) with and without $\mathrm{ZnO}-\mathrm{QDs}-\mathrm{SiO}_{2}$ and $\mathrm{ZnO}-\mathrm{NPs}-\mathrm{SiO}_{2}$; (c) Silica-coated $\mathrm{ZnO}$ nanomaterials' content optimization of NAGase activity assay within mastitic milk. Data are reported as mean \pm S.D. $(n \geq 3)$.

\subsection{Comparative Studies of NAGase Activity with and without ZnO-Nanomaterials}

The developed signal amplification concept for lysosomal activity evaluations by optimized TEOS coverage and the concentration of $\mathrm{ZnO}$ nanomaterials in correlation to $\mathrm{BM}$ severity was studied in real conditions. Milk samples obtained from the Volcani Center research herd were acquired from different animals (different udders), which represent the entire inflammatory spectrum, see Table 1. Strep. dysgalactiae, the predominant BM causing pathogen at three SCC levels (approximately 300, 800 and $>1000\left(\times 10^{3}\right)$ cells $\mathrm{mL}^{-1}$ identified as subclinical and clinical mastitis, respectively) were evaluated by the modified sensing concept. A healthy milk sample $(\mathrm{H})$ was considered as a control condition, negative bacteriological findings and SCC lower than $100\left(\times 10^{3}\right)$ cells $\mathrm{mL}^{-1}$, expecting insignificant lysosomal activity by the intrinsic NAGase load. All milk samples were subjected to similar treatment conditions and were evaluated in the presence of optimized $\mathrm{ZnO}$ nanomaterials' content. Figure 3 depicts the FL intensities output of NAGase catalytic activity in different milk qualities (healthy, subclinical and clinical statuses) with and without $\mathrm{ZnO}-\mathrm{QDs}-\mathrm{SiO}_{2}{ }^{\prime}$ s and $\mathrm{ZnO}-\mathrm{NPs}-\mathrm{SiO}_{2}{ }^{\prime} \mathrm{s}$ independent addition to the reaction solution. Significant increases in the FL intensities are attained for augmented SCC levels in the presence of $\mathrm{ZnO}-\mathrm{NPs}-\mathrm{SiO}_{2}(11.3 \pm 0.6,17.7 \pm 0.7,24.4 \pm 0.8$ a.u. for $\mathrm{S} 1, \mathrm{~S} 2, \mathrm{~S} 3$, respectively), while sample $\mathrm{H}$ showed low emitted values ( $6.6 \pm 0.6$ a.u.). The increased optical response indicates the overall NAGase concentration in the analyzed samples and thus implies 
the severity of the occurring $\mathrm{BM}$. A similar optical response is obtained for $\mathrm{ZnO}-\mathrm{QDs}-\mathrm{SiO}_{2}$ at similar escalating inflammatory statuses $(45.5 \pm 0.8,58.8 \pm 1.4,79.3 \pm 1.8$ a.u. for S1, S2, S3, respectively), with respect to the healthy condition of sample H (16.4 \pm 0.1 a.u.). These results further strengthen the correlation of NAGase lysosomal activity (FL values) as a BM-predicting indicator of various udder health conditions [2,13]. At this point, the conventional modified enzymatic assay without any addition of $\mathrm{ZnO}$-nanomaterials to the reaction solution was examined. A comparable FL intensities trend is shown in correlation to SCC increase $(2.2 \pm 0.4,5.5 \pm 0.9,6.5 \pm 1.2,11.3 \pm 0.4$ a.u. for H, S1, S2, S3, respectively) presenting escalading pathogenesis. It should be highlighted that the non-significant differentiation between S1 and S2 ( $t$-test, $p>0.05$ ) presents the actual limitation of the conventional assay in early-stage BM detection and severity classification. This technical drawback can be alleviated by improving the quantum efficiency and thus improving the sensitivity threshold. Overall, the optical results correspond with our previous reports and others, linking acute phase response due to an animal's inflammatory state with augmented NAGase activity $[1,6,10,35]$. Both signal-amplified assays can efficiently differentiate between the various milk qualities in correlation to SCC values based on the non-radiative energy transfer reaction from the nanomaterials ( $\mathrm{ZnO}-\mathrm{QDs}-\mathrm{SiO}_{2}$ and $\mathrm{ZnO}-\mathrm{NPs}_{-} \mathrm{SiO}_{2}$ ) to the lysosomal reaction products (4-MU).

Table 1. Infection status and somatic cell count (SCC) values of the analyzed milk samples.

\begin{tabular}{ccc}
\hline Sample $^{*}$ & SCC $\left(\times \mathbf{1 0 ^ { 3 }}\right)$ Cells $\mathbf{~ m L}^{-\mathbf{1}}$ & Bacteria \\
\hline H & 60 & N/A \\
\hline S1 & 350 & Strep. dysgalactiae \\
\hline S2 & 800 & Strep. dysgalactiae \\
\hline S3 & $>1000$ & Strep. dysgalactiae \\
\hline
\end{tabular}

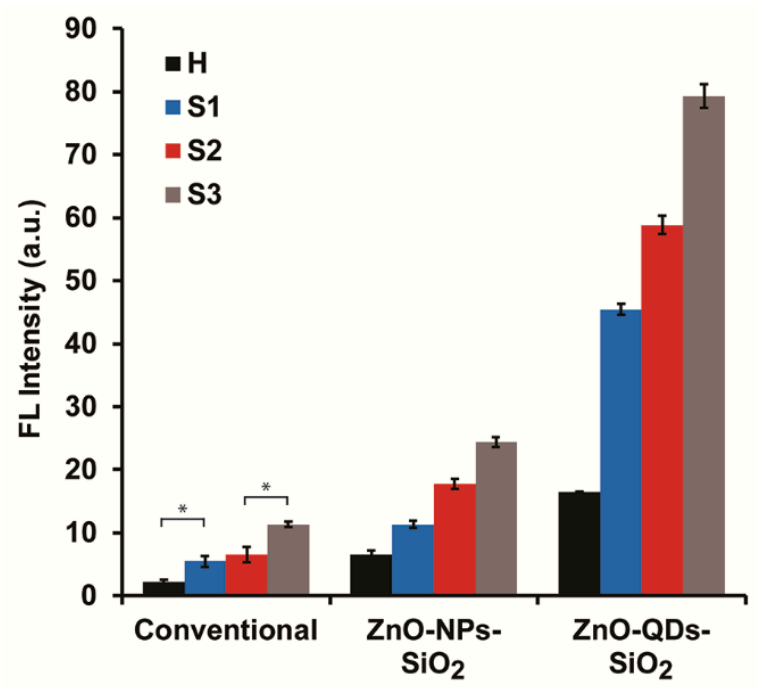

Figure 3. NAGase activity assay comparison in different milk qualities (healthy, subclinical and clinical $\mathrm{BM}$ ) with and without silica-coated $\mathrm{ZnO}$ nanomaterials' addition to the reaction solution. Data are reported as mean \pm S.D. $(n \geq 3)$. ${ }^{*}$ Significantly different $(t$-test, $p<0.05)$.

Next, calibration curves for all the noted assays for NAGase activity quantification under optimized conditions for each $\mathrm{ZnO}$ nanomaterial were prepared using a wide dynamic range of lysosomal reaction products. Figure $\mathrm{S} 4$ presents the optical response of the emitted radiation in response to 4-MU content escalation (0-100 $\mu \mathrm{M}$ spiked in control milk samples). The fitted regression equations for $\mathrm{ZnO}-\mathrm{QDs}-\mathrm{SiO}_{2}, \mathrm{ZnO}-\mathrm{NPs}-\mathrm{SiO}_{2}$ and the conventional assay within the linear range of 0-20 $\mu \mathrm{M}$ were obtained for all assays (Figure S4). The detection limits were assessed using $3 \mathrm{Sa} / \mathrm{m}$, 
where $\mathrm{Sa}$ is the standard of deviation and $\mathrm{m}$ is the slope of the linear portion, presenting values of 0.06 , 0.14 and $0.32 \mu \mathrm{M}$ for $\mathrm{ZnO}-\mathrm{QDs}-\mathrm{SiO}_{2}, \mathrm{ZnO}-\mathrm{NPs}-\mathrm{SiO}_{2}$ and the conventional assay, respectively. Moreover, all assays were spiked with $15 \mu \mathrm{M}$ of 4-MU in control milk samples while evaluating the recovery efficiencies. Table S1 summarizes the recoveries of all assays with respect to the spiked concentration presenting an acceptable range of $103 \%-109 \%$. Finally, the calculated enzymatic activities in the studied milk samples based on FL results are shown in Table 2. The estimated NAGase activity values support the FL studies in which lysosomal activity is increased with respect to SCC content and the severity of the induced inflammation. Significant differentiation between the inflammatory states is shown for all $\mathrm{ZnO}$ nanomaterials assays. NAGase activity values in the presence of $\mathrm{ZnO}-\mathrm{QDs}-\mathrm{SiO}_{2}$ overestimate $\mathrm{ZnO}-\mathrm{NPs}-\mathrm{SiO}_{2}$ for equivalent SCC levels $\left(0.94 \pm 0.02,1.21 \pm 0.03,1.64 \pm 0.04 \mu \mathrm{M} \mathrm{min}^{-1}\right.$ and $0.68 \pm 0.04$, $1.11 \pm 0.05,1.56 \pm 0.05 \mu \mathrm{M} \mathrm{min}{ }^{-1}$ for S1, S2, S3, respectively). As previously mentioned, this can be accredited to the electric field effect of surface plasmons favoring quantum nanostructure over an order of magnitude in size of $\mathrm{ZnO}-\mathrm{NPs}-\mathrm{SiO}_{2}$, thus presenting higher sensitivity [15,19]. Previous studies have shown that the influence of the curvature and coupling effects of nanomaterials provides a significant near-field enhancement in which the coupling becomes more significant with decreasing particle size [36-38]. The conventional assay (without $\mathrm{ZnO}$ nanomaterials) depicts a similar activity trend for SCC escalation without the possibility of differentiating the neighboring BM statuses of S1 and S2 samples ( $t$-test, $p>0.05$ ). This means that the conventional assay at the current methodological form cannot be utilized for early-stage detection of subclinical BM without improving the quantum efficiency by optically active nanomaterials. Despite the slight alteration in the absolute values by the different assays, the overall trend is of importance for assessing animals' precise inflammatory case, and therefore prescribing personal therapy treatment $[3,39]$. Moreover, it should be mentioned that both amplified and the conventional FL assays cannot indicate the specific bacterial species causing the BM; therefore complementary microbiological examination should be involved [6,9]. Overall, our experimental evidence played a crucial role in extrapolating the conventional NAGase assay by optically active nanomaterials, and acquiring intensified FL signals, for subclinical detection and identification.

Table 2. NAGase activity in milk samples with and without the addition of $\mathrm{ZnO}-\mathrm{QDs}-\mathrm{SiO}_{2}$ and $\mathrm{ZnO}-\mathrm{NPs}-\mathrm{SiO}_{2}$ onto the reaction assay.

\begin{tabular}{|c|c|c|c|}
\hline Sample ${ }^{* * * *}$ & $\begin{array}{l}\text { NAGase Activity } \\
\text { Conventional Assay } \\
\quad\left(\mu \mathrm{M} \text { min }^{-1}\right)\end{array}$ & $\begin{array}{c}\text { NAGase Activity } \\
\text { with } \mathrm{ZnO}-\mathrm{NPs}-\mathrm{SiO}_{2} \\
\left(\mu \mathrm{M} \mathrm{min}^{-1}\right)\end{array}$ & $\begin{array}{c}\text { NAGase Activity } \\
\text { with } \mathrm{ZnO}-\mathrm{QDs}-\mathrm{SiO}_{2} \\
\left(\mu \mathrm{M} \mathrm{min}^{-1}\right)\end{array}$ \\
\hline $\mathrm{H}$ & $0.30 \pm 0.05$ & $0.35 \pm 0.04$ & $0.33 \pm 0.01$ \\
\hline S1 & $0.73 \pm 0.12$ & $0.68 \pm 0.04$ & $0.94 \pm 0.02$ \\
\hline $\mathrm{S} 2$ & $0.86 \pm 0.16$ & $1.11 \pm 0.05$ & $1.21 \pm 0.03$ \\
\hline S3 & $1.50 \pm 0.06$ & $1.56 \pm 0.05$ & $1.64 \pm 0.04$ \\
\hline
\end{tabular}

${ }^{*}$ Healthy milk sample (H), mastitic milk samples (S). ${ }^{*}$ Strep. Dysgalactiae, S1, S2, S3, Data are reported as mean \pm S.D. $(n \geq 3)$.

\section{Conclusions}

Numerous BM diagnostic tests are routinely used to evaluate animals' health status based on inclusive parameters. Specifically, indicative biomarkers in milk can be utilized for early BM diagnosis and drug efficacy. In the present work, we disclose enhanced FL amplification of a conventional NAGase assay, a BM-predicting biomarker, by the addition of $\mathrm{ZnO}$ nanomaterials. Both $\mathrm{ZnO}-\mathrm{QDs}^{-} \mathrm{SiO}_{2}$ and $\mathrm{ZnO}-\mathrm{NPs}_{-} \mathrm{SiO}_{2}$ induce pronounced emission within real milk samples, thus revealing significant differentiation between various somatic cell counts for convenient early bio-diagnostics and health status evaluation. The developed optimized assay can be performed in real-life conditions (untreated milk, different SCC levels and pathogens) and within the entire inflammatory spectrum (healthy, subclinical and clinical BM). Herdsman or veterinarian can utilize augmented optical indication for 
personalized treatment, meaning only those cows requiring attention will get it. The methodology could be applied to study many other relevant composite systems with clinical implications by monitoring indicative biomarkers through signal amplification.

Supplementary Materials: The following are available online at http://www.mdpi.com/2079-4991/10/3/549/s1,

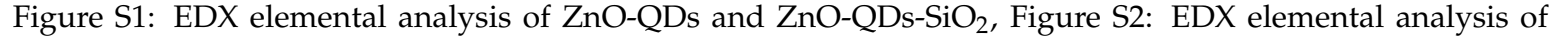
ZnO-NPs and ZnO-NPs-SiO 2 , Figure S3: Emission spectra of different TEOS amounts added to coat ZnO-NPs, Figure S4: Calibration curves of NAGase enzymatic activity product with and without ZnO nanomaterials. Table S1: NAGase enzymatic activity product recovery studies within control milk samples with and without $\mathrm{ZnO}$ nanomaterials.

Author Contributions: Conceptualization, G.S.; Methodology, N.R.N. and G.S.; Validation, N.R.N.; Formal Analysis, N.R.N. and G.S.; Investigation, N.R.N. and G.S.; Resources, G.S.; Writing-Original Draft Preparation, N.R.N.; Writing-Review and Editing, G.S.; Visualization, N.R.N. and G.S.; Supervision, G.S.; Project Administration, G.S.; Funding Acquisition, G.S. All authors have read and agreed to the published version of the manuscript.

Funding: This research was funded by the JCA Charitable Foundation, grant number 459-4610, and by The Israeli Chief Scientist of Ministry of Agriculture, grant number 20-07-0011.

Acknowledgments: In this section you can acknowledge any support given which is not covered by the author contribution or funding sections. This may include administrative and technical support, or donations in kind (e.g., materials used for experiments).

Conflicts of Interest: The authors declare no conflict of interest.

\section{References}

1. Kalmus, P.; Simojoki, H.; Pyörälä, S.; Taponen, S.; Holopainen, J.; Orro, T. Milk haptoglobin, milk amyloid A, and N-acetyl- $\beta$-d-glucosaminidase activity in bovines with naturally occurring clinical mastitis diagnosed with a quantitative PCR test. J. Dairy Sci. 2013, 96, 3662-3670. [CrossRef] [PubMed]

2. Pyörälä, S.; Hovinen, M.; Simojoki, H.; Fitzpatrick, J.; Eckersall, P.; Orro, T. Acute phase proteins in milk in naturally acquired bovine mastitis caused by different pathogens. Vet. Rec. 2011, 168, 535. [CrossRef]

3. Viguier, C.; Arora, S.; Gilmartin, N.; Welbeck, K.; O'Kennedy, R. Mastitis detection: Current trends and future perspectives. Trends Biotechnol. 2009, 27, 486-493. [CrossRef] [PubMed]

4. Seegers, H.; Fourichon, C.; Beaudeau, F. Production effects related to mastitis and mastitis economics in dairy cattle herds. Vet. Res. 2003, 34, 475-491. [CrossRef] [PubMed]

5. Mujawar, L.H.; Moers, A.; Norde, W.; van Amerongen, A. Rapid mastitis detection assay on porous nitrocellulose membrane slides. Anal. Bioanal. Chem. 2013, 405, 7469-7476. [CrossRef] [PubMed]

6. Hovinen, M.; Simojoki, H.; Pösö, R.; Suolaniemi, J.; Kalmus, P.; Suojala, L.; Pyörälä, S. $\mathrm{N}$-acetyl- $\beta$-D-glucosaminidase activity in cow milk as an indicator of mastitis. J. Dairy Res. 2016, 83, 219-227. [CrossRef]

7. Koess, C.; Hamann, J. Detection of mastitis in the bovine mammary gland by flow cytometry at early stages. J. Dairy Res. 2008, 75, 225-232. [CrossRef]

8. Sears, P.M.; McCarthy, K.K. Diagnosis of mastitis for therapy decisions. Vet. Clin. N. Am. Large Anim. Pract. 2003, 19, 93-108. [CrossRef]

9. Riffon, R.; Sayasith, K.; Khalil, H.; Dubreuil, P.; Drolet, M.; Lagacé, J. Development of a rapid and sensitive test for identification of major pathogens in bovine mastitis by PCR. J. Clin. Microbiol. 2001, 39, 2584-2589. [CrossRef]

10. Nirala, N.R.; Pinker, N.; Desitti, C.; Shtenberg, G. Milk haptoglobin detection based on enhanced chemiluminescence of gold nanoparticles. Talanta 2019, 197, 257-263. [CrossRef]

11. Nirala, N.R.; Shtenberg, G. Gold Nanoparticle Size-Dependent Enhanced Chemiluminescence for Ultra-Sensitive Haptoglobin Biomarker Detection. Biomolecules 2019, 9, 372. [CrossRef] [PubMed]

12. Kitchen, B.; Middleton, G.; Salmon, M. Bovine milk N-acetyl- $\beta$-D-glucosaminidase and its significance in the detection of abnormal udder secretions. J. Dairy Res. 1978, 45, 15-20. [CrossRef] [PubMed]

13. Nirala, N.R.; Shtenberg, G. Enhanced fluorescence of N-acetyl- $\beta$-D-glucosaminidase activity by ZnO quantum dots for early stage mastitis evaluation. Front. Chem. 2019. [CrossRef] [PubMed] 
14. El-Naggar, M.E.; Hassabo, A.G.; Mohamed, A.L.; Shaheen, T.I. Surface modification of $\mathrm{SiO}_{2}$ coated $\mathrm{ZnO}$ nanoparticles for multifunctional cotton fabrics. J. Colloid Interface Sci. 2017, 498, 413-422. [CrossRef] [PubMed]

15. Aslan, K.; Previte, M.J.; Zhang, Y.; Geddes, C.D. Metal-enhanced fluorescence from nanoparticulate zinc films. J. Phys. Chem. C 2008, 112, 18368-18375. [CrossRef] [PubMed]

16. El-Nahhal, I.M.; Salem, J.K.; Kuhn, S.; Hammad, T.; Hempelmann, R.; Al Bhaisi, S. Synthesis \& characterization of silica coated and functionalized silica coated zinc oxide nanomaterials. Powder Technol. 2016, 287, 439-446. [CrossRef]

17. Hagura, N.; Ogi, T.; Shirahama, T.; Iskandar, F.; Okuyama, K. Highly luminescent silica-coated ZnO nanoparticles dispersed in an aqueous medium. J. Lumin. 2011, 131, 921-925. [CrossRef]

18. Patra, M.; Manoth, M.; Singh, V.; Gowd, G.S.; Choudhry, V.; Vadera, S.; Kumar, N. Synthesis of stable dispersion of $\mathrm{ZnO}$ quantum dots in aqueous medium showing visible emission from bluish green to yellow. J. Lumin. 2009, 129, 320-324. [CrossRef]

19. Wang, T.; Centeno, A.; Darvill, D.; Pang, J.S.; Ryan, M.P.; Xie, F. Tuneable fluorescence enhancement of nanostructured $\mathrm{ZnO}$ arrays with controlled morphology. Phys. Chem. Chem. Phys. 2018, 20, 14828-14834. [CrossRef]

20. Zhao, D.; Song, H.; Hao, L.; Liu, X.; Zhang, L.; Lv, Y. Luminescent ZnO quantum dots for sensitive and selective detection of dopamine. Talanta 2013, 107, 133-139. [CrossRef]

21. Znaidi, L. Sol-gel-deposited ZnO thin films: A review. Mater. Sci. Eng. B 2010, 174, 18-30. [CrossRef]

22. Wu, Y.L.; Tok, A.; Boey, F.Y.C.; Zeng, X.T.; Zhang, X.H. Surface modification of ZnO nanocrystals. Appl. Surf. Sci. 2007, 253, 5473-5479. [CrossRef]

23. Tereshchenko, A.; Fedorenko, V.; Smyntyna, V.; Konup, I.; Konup, A.; Eriksson, M.; Yakimova, R.; Ramanavicius, A.; Balme, S.; Bechelany, M. ZnO films formed by atomic layer deposition as an optical biosensor platform for the detection of Grapevine virus A-type proteins. Biosens. Bioelectron. 2017, 92, 763-769. [CrossRef] [PubMed]

24. Guo, L.; Shi, Y.; Liu, X.; Han, Z.; Zhao, Z.; Chen, Y.; Xie, W.; Li, X. Enhanced fluorescence detection of proteins using $\mathrm{ZnO}$ nanowires integrated inside microfluidic chips. Biosens. Bioelectron. 2018, 99, 368-374. [CrossRef] [PubMed]

25. Akhtar, N.; Metkar, S.K.; Girigoswami, A.; Girigoswami, K. ZnO nanoflower based sensitive nano-biosensor for amyloid detection. Mater. Sci. Eng. C 2017, 78, 960-968. [CrossRef] [PubMed]

26. Shtenberg, G.; Massad-Ivanir, N.; Fruk, L.; Segal, E. Nanostructured porous Si optical biosensors: Effect of thermal oxidation on their performance and properties. ACS Appl. Mater. Interfaces 2014, 6, 16049-16055. [CrossRef]

27. Fang, L.; Wang, W.; Liu, Y.; Xie, Z.; Chen, L. Janus nanostructures formed by mesoporous silica coating Au nanorods for near-infrared chemo-photothermal therapy. J. Mater. Chem. B 2017, 5, 8833-8838. [CrossRef]

28. Park, Y.; Yoo, R.; Park, S.R.; Lee, J.H.; Jung, H.; Lee, H.-S.; Lee, W. Highly sensitive and selective isoprene sensing performance of $\mathrm{ZnO}$ quantum dots for a breath analyzer. Sens. Actuators B 2019, 290, 258-266. [CrossRef]

29. Tăbăcaru, A.; Muşat, V.; Ţigău, N.; Vasile, B.Ş.; Surdu, V.-A. Vinyltrimethoxysilane-modified zinc oxide quantum dots with tuned optical properties. Appl. Surf. Sci. 2015, 359, 766-773. [CrossRef]

30. Biswick, T.; Jones, W.; Pacuła, A.; Serwicka, E.; Podobinski, J. The role of anhydrous zinc nitrate in the thermal decomposition of the zinc hydroxy nitrates $\mathrm{Zn}_{5}(\mathrm{OH})_{8}\left(\mathrm{NO}_{3}\right)_{2} \cdot 2 \mathrm{H}_{2} \mathrm{O}$ and $\mathrm{ZnOHNO}_{3} \cdot \mathrm{H}_{2} \mathrm{O}$. J. Solid State Chem. 2007, 180, 1171-1179. [CrossRef]

31. Wang, Y.; Ma, T.; Ma, S.; Liu, Y.; Tian, Y.; Wang, R.; Jiang, Y.; Hou, D.; Wang, J. Fluorometric determination of the antibiotic kanamycin by aptamer-induced FRET quenching and recovery between $\mathrm{MoS}_{2}$ nanosheets and carbon dots. Microchim. Acta 2017, 184, 203-210. [CrossRef]

32. Kitchen, B.J.; Kwee, W.S.; Middleton, G.; Andrews, R.J. Relationship between the level of $\mathrm{N}$-acetyl- $\beta$-D-glucosaminidase (NAGase) in bovine milk and the presence of mastitis pathogens. J. Dairy Res. 1984, 51, 11-16. [CrossRef] [PubMed]

33. Ren, Z.; Li, X.; Guo, J.; Wang, R.; Wu, Y.; Zhang, M.; Li, C.; Han, Q.; Dong, J.; Zheng, H. Solution-based metal enhanced fluorescence with gold and gold/silver core-shell nanorods. Opt. Commun. 2015, 357, 156-160. [CrossRef] 
34. Gontero, D.; Veglia, A.V.; Bracamonte, A.G.; Boudreau, D. Synthesis of ultraluminescent gold core-shell nanoparticles as nanoimaging platforms for biosensing applications based on metal-enhanced fluorescence. RSC Adv. 2017, 7, 10252-10258. [CrossRef]

35. Nirala, N.R.; Harel, Y.; Lellouche, J.-P.; Shtenberg, G. Ultrasensitive haptoglobin biomarker detection based on amplified chemiluminescence of magnetite nanoparticles. J. Nanobiotechnol. 2020, 18, 6. [CrossRef] [PubMed]

36. Lang, X.; Guan, P.; Zhang, L.; Fujita, T.; Chen, M. Size dependence of molecular fluorescence enhancement of nanoporous gold. Appl. Phys. Lett. 2010, 96, 73701. [CrossRef]

37. Bardhan, R.; Grady, N.K.; Halas, N.J. Nanoscale Control of Near-Infrared Fluorescence Enhancement Using Au Nanoshells. Small 2008, 4, 1716-1722. [CrossRef]

38. Mahjoub, M.A.; Monier, G.; Robert-Goumet, C.; Réveret, F.; Echabaane, M.; Chaudanson, D.; Petit, M.; Bideux, L.; Gruzza, B. Synthesis and Study of Stable and Size-Controlled ZnO-SiO 2 Quantum Dots: Application as a Humidity Sensor. J. Phys. Chem. C 2016, 120, 11652-11662. [CrossRef]

39. Ferrero, F.; Valledor, M.; Campo, J. Screening method for early detection of mastitis in cows. Measurement 2014, 47, 855-860. [CrossRef]

(C) 2020 by the authors. Licensee MDPI, Basel, Switzerland. This article is an open access article distributed under the terms and conditions of the Creative Commons Attribution (CC BY) license (http://creativecommons.org/licenses/by/4.0/). 